\title{
The Flotation Separation of Magnesite and Limonite Using an Amine Collector
}

\author{
Jiahong Han $\mathbb{D},{ }^{1,2}$ Xiaoan Li $\mathbb{D}, 2$ Shujuan Dai $\mathbb{D}^{2}$, and Guozhen Liu $\mathbb{D}^{3}$ \\ ${ }^{1}$ Chaoyang Teachers College, Liaoning, China \\ ${ }^{2}$ School of Chemical Engineering, University of Science and Technology Liaoning, Liaoning, China \\ ${ }^{3}$ Hebei Zhongke Tongchuang Technology and Development Co. Ltd, Hebei, China
}

Correspondence should be addressed to Shujuan Dai; dsj@ustl.edu.cn

Received 26 March 2020; Accepted 6 January 2021; Published 8 March 2021

Academic Editor: Adrián Bonilla-Petriciolet

Copyright (C) 2021 Jiahong Han et al. This is an open access article distributed under the Creative Commons Attribution License, which permits unrestricted use, distribution, and reproduction in any medium, provided the original work is properly cited.

In order to reduce the iron impurities in magnesite ore and improve the purity of magnesium products, the difference in floatability between magnesite and limonite has been studied by using mixtures with a collecting agent-KD (cationic amine collectors, containing soluble components). Sodium hexametaphosphate, $\mathrm{pH}$, sodium silicate, and sodium carboxymethyl cellulose were used as regulators. Adsorption mechanisms of the reagents on minerals were analyzed by a zeta potential analyzer and infrared spectroscopy. Sodium silicate increased the floatability of both minerals at 11.6. All the three regulators reduced the zeta potential of both minerals, while KD increased the zeta potential of magnesite and decreased the zeta potential of limonite. All the three regulators were likely chemically adsorbed on the surface of both minerals; KD has electrostatic adsorption on the surface of the minerals.

\section{Introduction}

Magnesite raw materials with iron impurities have a great impact on fire resistance. Iron impurities react with $\mathrm{CaO}$, generating a low-melting point material, while iron oxide is reduced to the metallic iron, making refractory products in the formation of melting holes [1]. The presence of iron impurity degrades magnesite products [2]. The content of iron impurities in magnesite raw ore is low, but the existence of iron is more complicated. The observation by a polarization microscope shows that the primary iron minerals in the ore are pyrite, pyrrhotite, magnetite, and hematite and after weathering, the vast majority of iron sulfide minerals is converted into limonite with iron sulfide minerals only as a residue [3-6]. Limonite is a common impurity in magnesite ore, which is the main component of the natural mixture of ferrous oxides [7].

At present, there are some reports about the technology of removing iron from magnesite at home and abroad. The iron in magnesite ore includes the iron in the raw ore and the iron impurities entrapped in the crushing process. The iron entrapped in the crushing and grinding can be partially removed by magnetic separation processes, but nonmagnetic iron and weak magnetic iron are difficult to be separated using a single magnetic separation method. The iron removal from magnesite is mainly carried out by strong magnetic separation. Besides, the content of iron is also reduced to a certain degree during the silicon removal purification of magnesite ore [8]. The DESCOS superconducting magnetic separator operating at a magnetic field intensity of $3.2 \mathrm{~T}$ at the Tutluca Magnesite Concentrator in Turkey processes a magnesite ore of a particle size of 100 to $4 \mathrm{~mm}$ with about $20 \%$ of $\mathrm{SiO}_{2}$ and $4 \%$ of $\mathrm{Fe}_{2} \mathrm{O}_{3}$. Dry roughing was conducted to obtain a product containing not more than $1.5 \%$ of $\mathrm{SiO}_{2}$ and not more than $0.3 \%$ of $\mathrm{Fe}_{2} \mathrm{O}_{3}$ [9]. Some research abroad focuses on magnetic separation of magnesite ore using magnetic seeds. At the appropriate $\mathrm{pH}$ level, the surfaces of serpentine and limonite are firstly modified with surfactants and the magnetic seeds are subsequently added to allow the magnetic seeds to selectively adhere to the serpentine and limonite surfaces, resulting in a large difference of magnetic susceptibility between the minerals for following magnetic 
separation [10]. Shenyang Aluminum and Magnesium Engineering and Research Institute conducted a beneficiation study on a low-grade magnesite ore with a TFe content of $1.20 \%$ in the Jiuquan area of Gansu Province. The ironbearing minerals in the ore are mainly hematite, besides magnetite, limonite, and pyrite. An SHP-500 strong magnetic separator was used to remove the iron from the ore, followed by two stages of positive flotation. The resulting concentrate has a TFe content of $0.94 \%$ and a MgO content of $46.05 \%$ [11]. Mineral processing of the cryptocrystalline magnesite ore in Iran was carried out by Wuhan University of Science and Technology with an iron content of $1.05 \%$. An XCSQ$50 \times 70$ wet magnetic separator was used to remove iron before flotation of the ore. It is shown that two stages of magnetic separation at $0.5 \mathrm{~T}$ reduced the iron down to $0.5 \%$ [12]. At present, most iron minerals with less magnetic susceptibilities such as limonite are strengthened to be magnetic by magnetization roasting [13-17]. Zhang et al. conducted flotation purification of magnesite with mechanism analysis [18]. The main impurities in magnesite ore were silicon, calcium, and iron. Cationic reverse flotation was usually used to remove silicon from magnesite ore; then, anion flotation was used to remove calcium and some silicon when the content of impurities was high [19]. It is necessary to remove iron during the removal of silicon by cationic reverse flotation.

According to the characteristics of some high-iron magnesite resources in China, it is important to carry out a study on flotation separation and the mechanism of magnesite and limonite. Through a single-mineral flotation test, artificial mixed-mineral floating election test, potentiodynamic test, and infrared spectroscopy, the flotation behavior of magnesite and limonite and the effects of sodium hexametaphosphate, sodium silicate, and sodium carboxymethyl cellulose (CMC) on magnesite and limonite were investigated. The flotation behaviors of magnesite and limonite are analyzed. The research results are of guiding significance to the production of related enterprises, improving the comprehensive utilization of resources.

\section{Materials and Methods}

\subsection{Material}

2.1.1. The Single-Magnesite Mineral. The single-magnesite sample was a stock from the mineral processing laboratory of Liaoning University of Science and Technology. After crushing, sorting, grinding $(\mathrm{XMB}-\Phi 200 \times 240)$, and screening, the single-magnesite sample was washed and dried for experimental use at a particle size of $0.021-0.075 \mathrm{~mm}$. Multielement analysis of the mineral sample is shown in Table 1, and X-ray diffraction test results are shown in Figure 1.

As can be seen in Table 1, the single-magnesite sample contained $47.20 \% \mathrm{MgO}$ and the $\mathrm{MgCO}_{3}$ content was 98.90\%. The XRD results from Figure 1 also indicate that the major mineral is magnesite.

2.1.2. The Single-Limonite Mineral. The single-limonite sample was a stock from the mineral processing laboratory of University of Science and Technology Liaoning. After
TABle 1: Chemical composition analysis of magnesite.

\begin{tabular}{lccccc}
\hline Chemical composition & $\mathrm{CaO}$ & $\mathrm{Fe}_{2} \mathrm{O}_{3}$ & $\mathrm{Al}_{2} \mathrm{O}_{3}$ & $\mathrm{SiO}_{2}$ & $\mathrm{MgO}$ \\
\hline Content (\%) & 0.25 & 0.32 & 0.34 & 0.19 & 47.20 \\
\hline
\end{tabular}

crushing, sorting, grinding, and sieving, the limonite sample was washed and dried for the subsequent use with a particle size of $0.021-0.104 \mathrm{~mm}$. As can be seen in Table 2, the content of limonite reached more than $95 \%$, with a small amount of other impurities, showing high purity of limonite in the sample, in good agreement with the XRF result in Figure 2.

\subsubsection{Test Methods}

(1) The Flotation Test. The floatability difference between magnesite and limonite was investigated in a single-mineral flotation test using sodium hexametaphosphate, sodium silicate, and $\mathrm{CMC}$ as modification agents to the collector $\mathrm{KD}$ and by adjusting the pulp $\mathrm{pH}$ value with $1 \% \mathrm{HCl}$ or $1 \%$ $\mathrm{NaOH}$. The test was carried out on a $30 \mathrm{ml}$ XFGC air-filled tank flotation machine, with $2 \mathrm{~g}$ of the mineral sample for each flotation test. In the flotation test, $\mathrm{HCl}$ or $\mathrm{NaOH}$ was added to adjust the $\mathrm{pH}$ value of the slurry, modification agents were added for 3 min stirring, and the collector was added for $3 \mathrm{~min}$ agitation before froth scraping. The singlemineral test process is shown in Figure 3. After flotation, foam products and unfloated products were filtered, dried, and weighed.

(2) The Electric Potential Test. Determination of electric potential was conducted using a JS94H-based microelectrophoresis apparatus to measure the surface potential of single minerals under different environments. The sample was ground to $5 \mu \mathrm{m}$ or less using a ZXM-1 vibrating mill. A $250 \mathrm{mg}$ sample was taken into $250 \mathrm{ml}$ volumetric flask, to make the slurry. Take $30 \mathrm{ml}$ pulp in a beaker, adjust the amount of each agent to be tested, and each time, place $0.5 \mathrm{ml}$ liquid in the electrophoresis tank. A microelectrophoresis meter was used to measure the electrokinetic potential, each survey site was measured 5 times, and the remaining values were averaged after the number of interference was removed.

(3) Infrared Spectrometry. Single minerals were tested by a certain percentage added to a certain dose of flotation reagents in aqueous solution at a varied $\mathrm{pH}$ value. The slurry was fully stirred and filtered, washed with distilled water, and air dried. $\mathrm{KBr}$ press was prepared with the appropriate proportion of $\mathrm{KBr}$ and minerals. The pressed tablet was placed in an infrared spectrometer (Nicolet 380 FT-IR, Thermo Electron Corporation) for measurement.

(4) X-Ray Diffraction Measurement. The sample to be tested was ground to $45 \mu \mathrm{m}$ or less and tested in an X-ray diffractometer (PW3040/60, Panalytical BV, the Netherlands) at ambient temperature. Diffraction pattern analysis was done according to the PDF2-2004 Card Version of the Joint Diffraction Data Standards Joint Commission International 


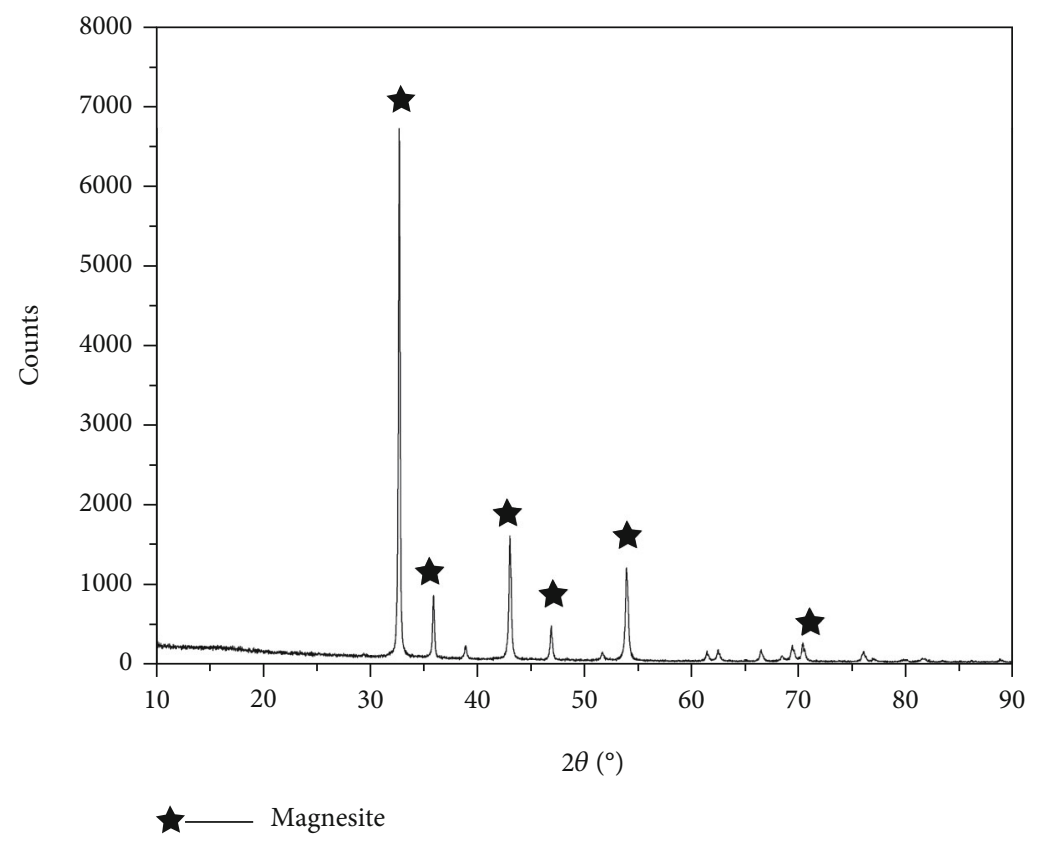

Figure 1: X-ray diffraction pattern of the magnesite sample.

TABLe 2: Chemical composition analysis of limonite.

\begin{tabular}{lccccccc}
\hline Chemical composition & $\mathrm{Fe}_{2} \mathrm{O}_{3}$ & $\mathrm{SiO}_{2}$ & $\mathrm{Al}_{2} \mathrm{O}_{3}$ & $\mathrm{MgO}$ & $\mathrm{P}_{2} \mathrm{O}_{5}$ & $\mathrm{SO}_{3}$ & $\mathrm{TiO}_{2}$ \\
\hline Content (\%) & 95.10 & 1.50 & 2.00 & 0.402 & 0.13 & 0.228 & 0.423 \\
Chemical composition & $\mathrm{Cl}$ & $\mathrm{K}_{2} \mathrm{O}$ & $\mathrm{CaO}$ & $\mathrm{MnO}$ & $\mathrm{CuO}$ & $\mathrm{Cr}_{2} \mathrm{O}_{3}$ & $\mathrm{As}_{2} \mathrm{O}_{3}$ \\
Content (\%) & 0.019 & 0.011 & 0.038 & 0.0377 & 0.021 & 0.0349 & 0.0366 \\
\hline
\end{tabular}

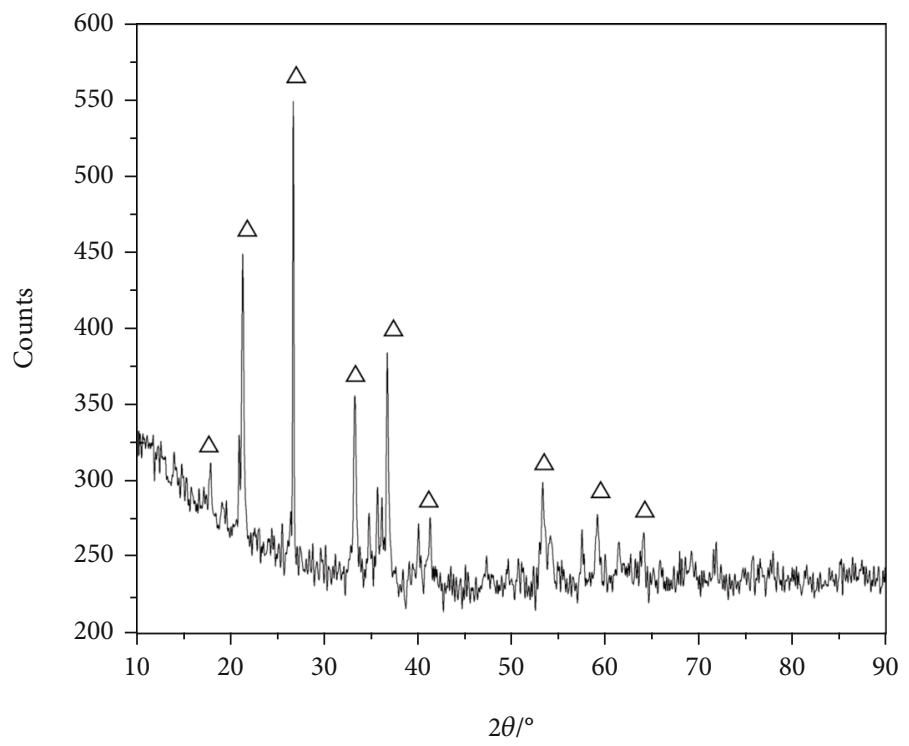

$\triangle$ Limonite

Figure 2: X-ray diffraction pattern of the limonite sample. 


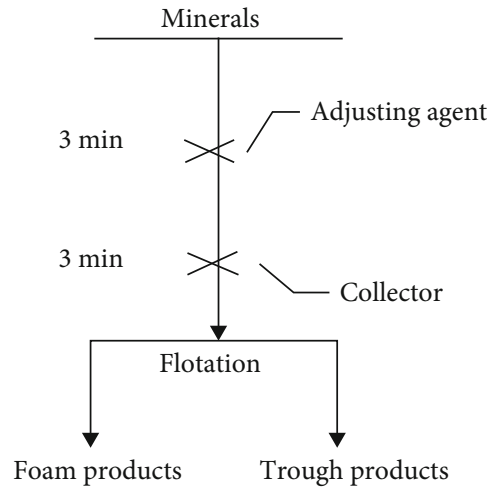

FIGURE 3: Single-mineral flotation test flow chart.

Diffraction Data Center (JCPDS-ICDD), and data analysis was performed using X'Pert HighScore Plus software.

\section{Results and Discussion}

\subsection{Flotation of Single Minerals Using Collector KD}

3.1.1. Influences of the $p H$ Value on the Floatability of Magnesite and Limonite. The collector $\mathrm{KD}$ was $150 \mathrm{mg} / \mathrm{l}$, and the $\mathrm{pH}$ value of pulp was adjusted. Flotation tests were carried out on single minerals of magnesite and limonite at different $\mathrm{pH}$ values, and the difference of the $\mathrm{pH}$ value of these two minerals in the system of the amine collector was studied. The test results are shown in Figure 4.

As can be seen from Figure 4, with the increase of the $\mathrm{pH}$ value, the recovery of magnesite appeared to have two peaks at $\mathrm{pH}$ of 5 and 11.6 at recovery rates $66.40 \%$ and $74.35 \%$, respectively. When the $\mathrm{pH}$ value was 7.4 , the floatation ratio of magnesite was $35.4 \%$. While the rising rate of limonite showed a trend of initial increase and following decrease with the change of the $\mathrm{pH}$ value, the rising rate of limonite reached the maximum when the $\mathrm{pH}$ value was 7.9 and the maximum floatation ratio was $17.6 \%$. At $\mathrm{pH}$ of 2.2 and 11.6, the floatation ratios were $2.35 \%$ and $3.25 \%$, respectively, for limonite. In the $\mathrm{KD}$ amine collector system, the $\mathrm{pH}$ value influenced the floatation ratios of magnesite and limonite in the studied $\mathrm{pH}$ range. The flotation rate of magnesite was much higher than that of limonite. Thus, it is suggested to remove limonite by positive flotation of magnesite at the $\mathrm{pH}$ value of 5 or 11.6. According to the current technical process of the purification of a magnesite mine, it is reverse-positive combined flotation with the reverse flotation of silicon removal when the $\mathrm{pH}$ value is $5[20,21]$. Thus, the following tests were used for flotation of iron at $\mathrm{pH}$ of 11.6.

\subsubsection{Influences of KD Dosage on the Floatability of} Magnesite and Limonite. The $\mathrm{pH}$ value of the slurry was adjusted to 11.6 with $\mathrm{NaOH}$, and the effect of the collector on the flotation effect of the two minerals was investigated. As can be seen in Figure 4, with the increase of KD, the floatation ratio of magnesite increased continuously. When the $\mathrm{KD}$ dosage was increased to $150 \mathrm{mg} / \mathrm{l}$, the floatation ratio of magnesite was $74.35 \%$ and that of limonite was $3.25 \%$. When the dosage of $\mathrm{KD}$ was increased to $250 \mathrm{mg} / \mathrm{l}$, the floatation ratio of magnesite reached $87.8 \%$ and the floatation ratio of limonite also increased with the increase of $\mathrm{KD}$ dosage at a maximum floatation ratio of only $4.55 \%$. Considering the dosage and separation effects of flotation, at $\mathrm{pH}$ of 11.6 and $\mathrm{KD}$ dosage of $150 \mathrm{mg} / \mathrm{l}$, the positive flotation magnesite was suggested to remove iron.

3.1.3. Influence of the Adjustment Agent on the Floatability of Magnesite and Limonite. The addition of a modifier is beneficial to the effect of the collector on the mineral. In this study, the effects of sodium hexametaphosphate, sodium silicate, and CMC on the flotation of two minerals were studied in $\mathrm{KD}$. The pulp $\mathrm{pH}$ value was adjusted to 11.6 , the $\mathrm{KD}$ dosage was $150 \mathrm{mg} / \mathrm{l}$, and the amounts of sodium hexametaphosphate, sodium silicate, and CMC were changed to study the effect of the flotation of the two minerals in the amine collector system. The test results are shown in Figure 5.

As can be seen in Figure 5, with the amount of sodium hexametaphosphate being increased from 0 to $40 \mathrm{mg} / \mathrm{l}$ and then to $200 \mathrm{mg} / \mathrm{l}$, the floatation ratio of magnesite decreased from $74.35 \%$ to $19.40 \%$ first and then slightly increased $21.90 \%$. The floatation ratio showed a slight upward trend at first and then increased slightly. The floatation rate of limonite decreased from $3.25 \%$ to $0.05 \%$, but the recovery of magnesite dropped more than that of limonite. The addition of sodium hexametaphosphate reduced the floatability difference between magnesite and limonite; there existed electrostatic adsorption which was not conducive to the flotation separation of two minerals, so the collector KD was not suitable for sodium hexametaphosphate as magnesite and limonite flotation-adjusting agents of the separation.

With the amount of sodium silicate being increased from 0 to $150 \mathrm{mg} / \mathrm{l}$ and then increased to $250 \mathrm{mg} / \mathrm{l}$, the floatation ratio of magnesite decreased from $74.35 \%$ to $61.65 \%$ and then to $67.85 \%$ and then decreased and finally increased slightly. The floatation rate of limonite fluctuated between $2.3 \%$ and $4.9 \%$, with the increase of the sodium silicate content. Therefore, the addition of sodium silicate can still ensure the effective inhibition of limonite when magnesite is floated and the sodium silicate can be used as an adjusting agent for the flotation separation of two minerals.

A small amount of CMC can strongly inhibit the floating rate of the magnesite; at a CMC dosage of $40 \mathrm{mg} / \mathrm{l}$, the magma floatation ratio was only $9.45 \%$ and the limonite floatation ratio had little change with the carboxymethyl cellulose sodium being increased. The CMC dosage was $40 \mathrm{mg} / \mathrm{l}$, and the maximum floatation ratio was $4.2 \%$. This indicates that the addition of CMC did not reduce the floating difference between the two minerals and CMC was not a suitable adjusting agent for $\mathrm{KD}$ flotation of magnesite and limonite.

In summary, less sodium hexametaphosphate and CMC dosage strongly inhibited the rise of magnesite. Thus, the magnesite floatation ratio was maintained at a relatively low level. Although sodium silicate also inhibited the floating of magnesite to a certain extent, its inhibitory effect was weak, with little impact on the flotation separation of these two minerals. Therefore, in the actual removal of iron from magnesite, sodium silicate was selected as an adjusting agent. 


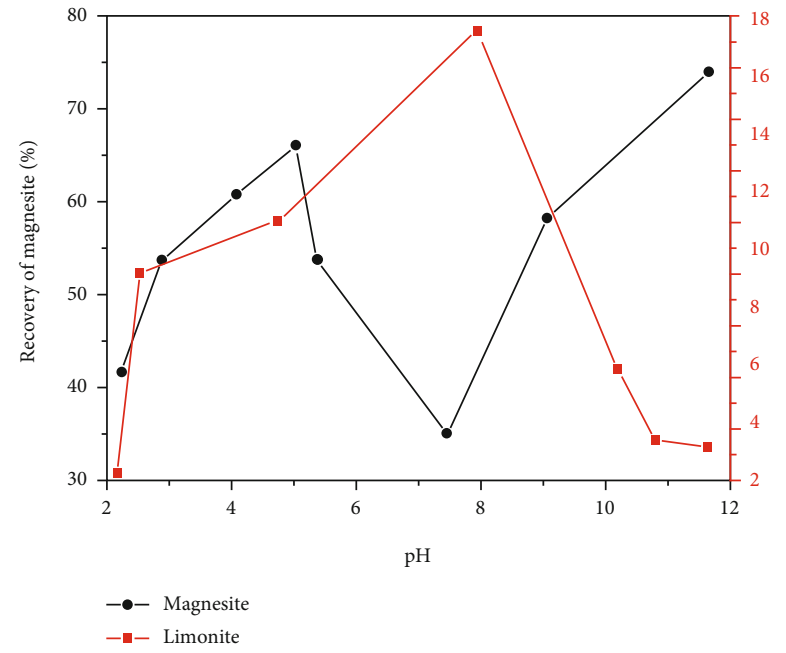

(a)

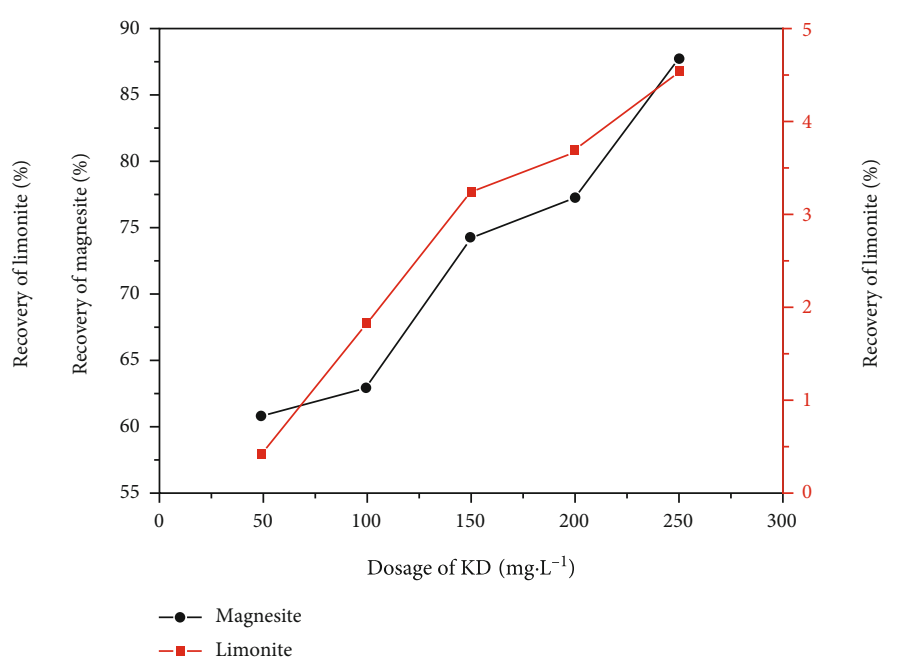

(b)

FIGURE 4: Effects of $\mathrm{pH}(\mathrm{a})$ and $\mathrm{KD}$ (b) on the flotation rate of magnesite and limonite.

3.1.4. Flotation Separation of the Artificial Mineral Mixture Using $K D$. In order to verify the effect of sodium silicate separation of two kinds of minerals, an artificial mixture of $2 \mathrm{~g}$ was made containing $99 \%$ magnesite and $1 \%$ limonite. The artificial mixed-ore grade was $0.92 \%$ iron, a test $\mathrm{pH}$ value of 11.6 , and a KD dosage of $150 \mathrm{mg} / \mathrm{l}$. The test results are shown in Figure 6.

As can be seen in Figure 6, when sodium silicate was $50 \mathrm{mg} / \mathrm{l}$, the concentrate yield in the artificial mixed-ore was $76.97 \%$ and the iron grade was $0.33 \%$. When the amount of sodium silicate was increased to $100 \mathrm{mg} / \mathrm{l}$, the iron grade decreased down to $0.32 \%$. The artificial mixed-flotation separation effect was better, showing the same trend of the two mineral floatation ratios in single-mineral flotation tests. Flotation of concentrate production decreased first, then there was a certain degree of recovery, and iron grade first declined and then tended to be stable. Compared with the singlemineral test, the floatation rate of limonite in the mixed-ore test further decreased, which is due to the preferential adsorption of $\mathrm{KD}$ to magnesite.

\subsection{Reagents on the Mineral Surface Electrical Properties}

3.2.1. The Effect of pH on the Electrical Properties of Mineral Surfaces. Changes in mineral potential on the surface will affect the adsorption between the reagents and the mineral, thus affecting the mineral flotation separation. Studying electrical changes on the surface of minerals allows the analysis of the mechanism of action of reagents and minerals [22, 23]. Taking magnesite and limonite single minerals as research objects, the $\mathrm{pH}$ value was adjusted with $\mathrm{HCl}$ or $\mathrm{NaOH}$ and zeta potential of two minerals at different $\mathrm{pH}$ values were determined. The measurement results are shown in Figure 7.

With the increase of the $\mathrm{pH}$ value, the electric potential of the magnesite surface first decreased and then increased. When the $\mathrm{pH}$ value increased from 2.1 to 11 , the electric potential of magnesite decreased from $15.05 \mathrm{mV}$ to $-13.91 \mathrm{mV}$. When the $\mathrm{pH}$ value was 6.0, the magnesite electrical potential is zero, con- sistent with references $[24,25]$. When the medium $\mathrm{pH}$ is greater than the zero point of magnesite $(\mathrm{pH}=6.0)$, the surface of magnesite is negatively charged. When the $\mathrm{pH}$ is 12 , the magnetization potential of magnesite is $6.68 \mathrm{eV}$ and the kinetic potential starts to appear slightly, probably due to the larger ionic strength of the solution, which results in the compression of the electrical double layer on the mineral surface. It was assumed that the high ionic strength of the solution leads to the compression of the double electric layer on the surface of the mineral, thus reducing the absolute value of the electric potential on the surface of the mineral; it was also assumed that because the zero electric point of magnesium hydroxide is $\mathrm{pH}=12.0$, a number of hydroxide precipitates was generated on the surface of the mineral in the strong alkaline solution $[26,27]$. The zeta potential of limonite decreases with the increase of the $\mathrm{pH}$ value. When the $\mathrm{pH}$ value increases from 2.0 to 11.9 , the electromotive potential of limonite is reduced from $38.43 \mathrm{mV}$ to $-18.74 \mathrm{mV}$. When $\mathrm{pH}$ value is 7.5 , the electromotive potential of limonite is zero, consistent with references $[28,29]$.

\subsubsection{The Effect of Sodium Hexametaphosphate on Electrical} Properties of the Mineral Surface. The effects of adding different amounts of sodium hexametaphosphate on the zeta potential of magnesite and limonite surface were investigated. The results are shown in Figure 8.

It can be seen in Figure 8 that sodium hexametaphosphate significantly reduced the zeta potential of the two minerals by electrostatic adsorption. When sodium hexametaphosphate concentration was $20 \mathrm{mg} / \mathrm{l}$ and the $\mathrm{pH}$ value increased from 2.0 to 11.0, the electromotive potential of magnesite reduced from $-8.43 \mathrm{mV}$ to $-35.48 \mathrm{mV}$. When the $\mathrm{pH}$ was increased to 12.0 , the magnetization potential of magnesite slightly increased to $-25.07 \mathrm{mV}$. When the concentration of sodium hexametaphosphate was $40 \mathrm{mg} / \mathrm{l}$ and the $\mathrm{pH}$ was increased from 2.0 to 11 , the electromotive potential of magnesite decreased from $-19.28 \mathrm{mV}$ to $-37.48 \mathrm{mV}$ and the $\mathrm{pH}$ value was further increased to 11.9 and the magnetron potential 


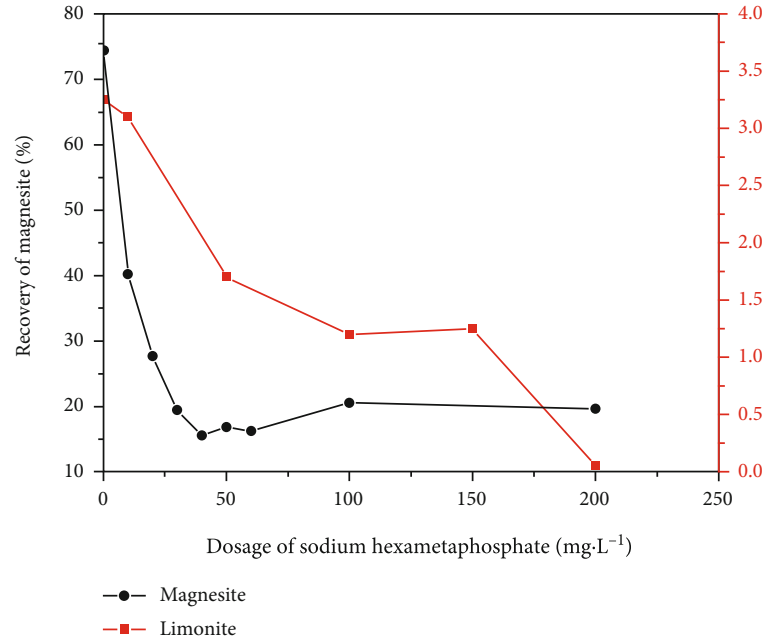

(a)

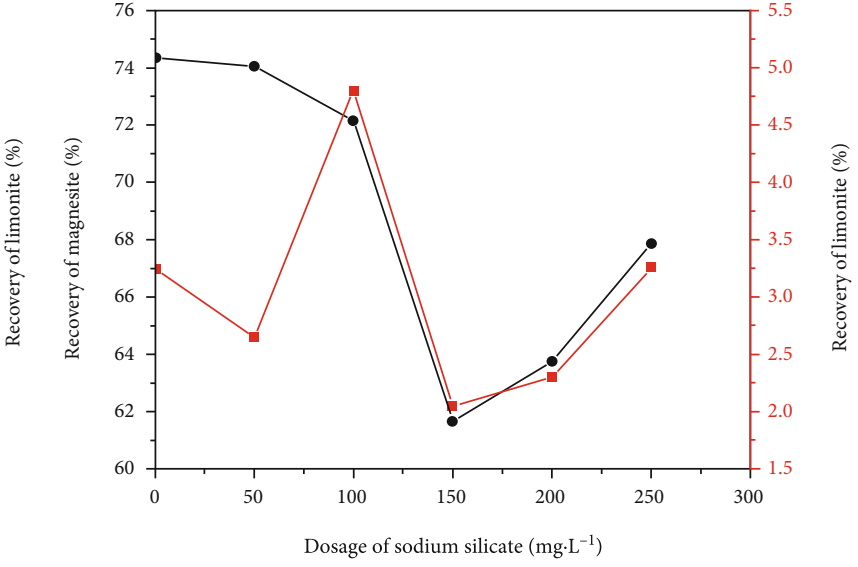

(b)

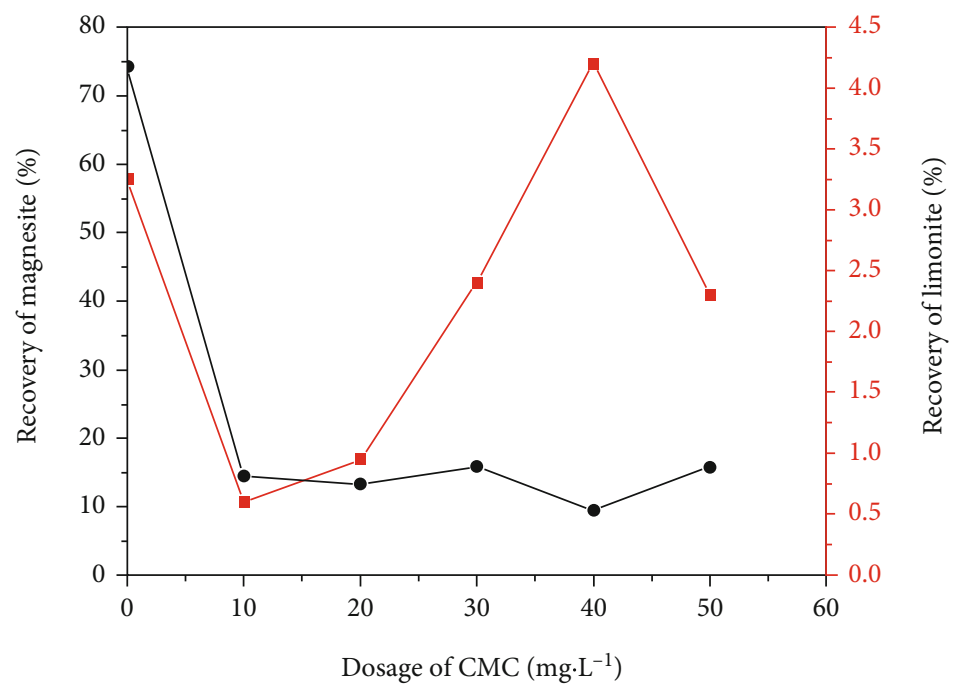

(c)

FIGURE 5: Effects of sodium hexametaphosphate (a), sodium silicate (b), and CMC (c) on the floatation ratios of magnesite and limonite.

increased slightly to $-26.87 \mathrm{mV}$. After the effect of sodium hexametaphosphate, the electric potential of magnesite in the same $\mathrm{pH}$ value was negative. The phosphate likely adsorbed on the magnesite surface, so that the magnesite potential dropped. The amount of sodium hexametaphosphate was further increased, the sodium potential increased further with the same tendency, and the electromotive potential decreased slightly. The electromotive potential of limonite decreased from $-17.19 \mathrm{mV}$ to $-33.43 \mathrm{mV}$. When the concentration of sodium hexametaphosphate was $20 \mathrm{mg} / \mathrm{l}$ and the $\mathrm{pH}$ was increased from 2.2 to $11.2 \mathrm{mV}$, and further to a $\mathrm{pH}$ of 12 , the limonite electromotive potential slightly increased to $-25.75 \mathrm{mV}$. With an increased sodium hexametaphosphate concentration of $40 \mathrm{mg} / \mathrm{l}$, the $\mathrm{pH}$ value increased from 2.2 to 11.2. The limonite electric potential decreased from $-7.74 \mathrm{mV}$ to $-39.35 \mathrm{mV}$. When the $\mathrm{pH}$ value was further increased to 12 , the electromotive potential of limonite increased to $-28.80 \mathrm{mV}$, therefore adding a small amount of sodium hexametaphosphate could make the electromotive potential value of the two minerals in the $\mathrm{pH}$ range become a negative value and the greater the concentration, the greater the reduction in the electromotive potential value.

\subsubsection{The Effect of Sodium Silicate on the Electrical Properties} of Mineral Surfaces. The effects of adding different amounts of sodium silicate on the zeta potential of magnesite and limonite were investigated. The results are shown in Figure 9.

As can be seen in Figure 9, the addition of sodium silicate reduced the electromotive potential of magnesite by electrostatic adsorption, shifting its zero point to the left, and the greater the concentration of sodium silicate, the more the shifting to the left. When the sodium silicate dosage was $100 \mathrm{mg} / \mathrm{l}$, the zero point of magnesite decreased from 6.0 to 4.0. When the amount of sodium silicate increased to $200 \mathrm{mg} / \mathrm{l}$, the zero point of magnesite further decreased to 3.5. When the sodium silicate dosage was $100 \mathrm{mg} / \mathrm{l}$, the electromotive potential value of limonite became negative within the measured $\mathrm{pH}$ range. With the further increase of sodium silicate, the change of electric potential becomes smaller. 


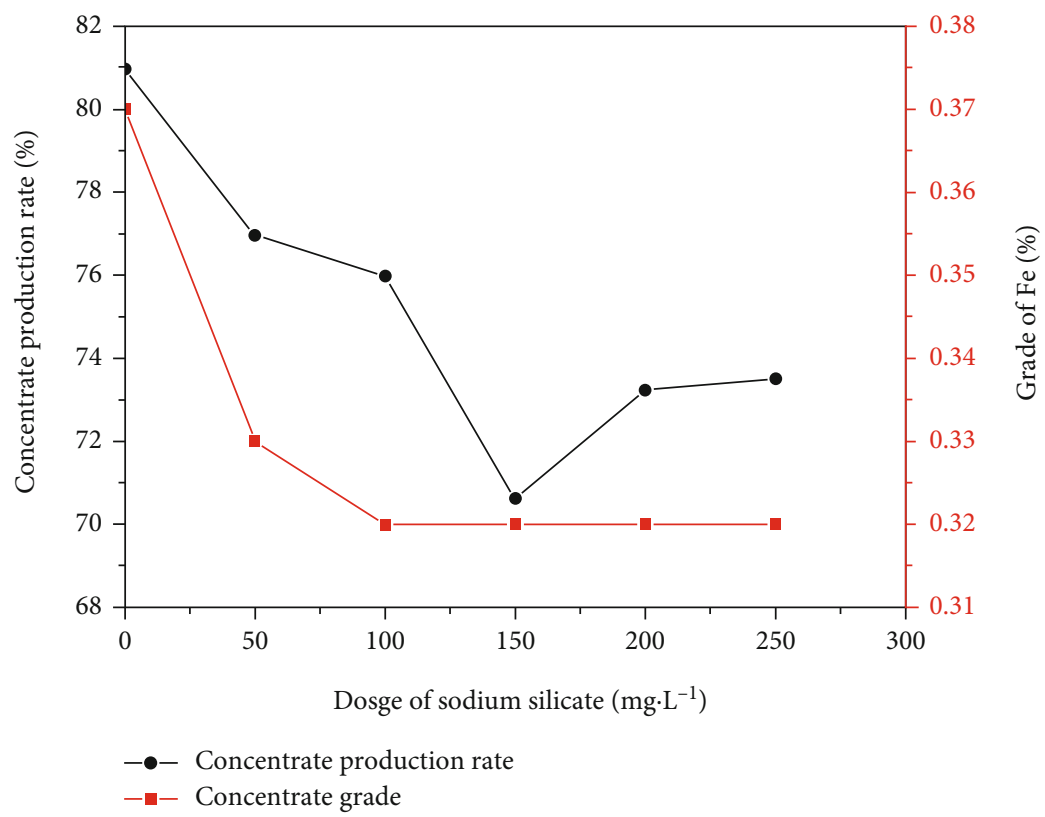

FIGURE 6: Effect of sodium silicate on artificial mixed-ore test results.

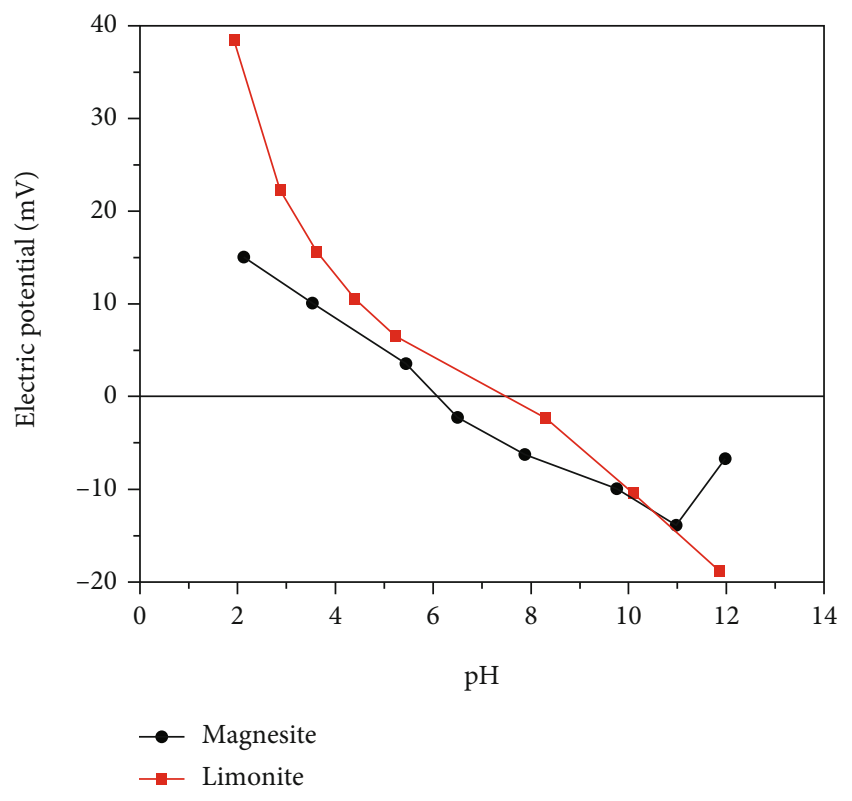

Figure 7: Magnesite and limonite zeta potential.

3.2.4. The Effect of CMC on the Electrical Properties of Mineral Surfaces. The effects of adding different amounts of $\mathrm{CMC}$ on the zeta potential of magnesite and limonite surface were investigated. The results are shown in Figure 10.

As can be seen in Figure 10, CMC significantly lowered the electric potential of magnesite by electrostatic adsorption under acidic conditions. When the CMC concentration was $20 \mathrm{mg} / \mathrm{l}$, the magnesite magnetoelectricity potential value was negative and the increase of $\mathrm{pH}$ caused the electric potential value to slightly decline. In the alkaline region, the addition of CMC instead of magnetizing the electric potential value increased in carboxymethyl. The effect of CMC on the decrease of the electric potential value of limonite was also remarkable. When the CMC concentration was $20 \mathrm{mg} / \mathrm{l}$, the electric potential value of limonite became negative.

3.2.5. KD on the Electrical Properties of the Mineral Surface. The effect of adding KD with different dosages on the zeta potential of magnesite and limonite was investigated. The results are shown in Figure 11.

It can be seen in Figure 11 that KD increased the magnetron potential of magnesite and increased with higher $\mathrm{KD}$ concentration. When the KD concentration was $100 \mathrm{mg} / \mathrm{l}$, the zero point of magnesite was 6.0 to 9.0 . When the KD concentration was increased to $200 \mathrm{mg} / \mathrm{l}$, the zero point of magnesite further increased to 9.6. The electrokinetic potential of magnesite moves to positive in the $\mathrm{pH}$ range of 2.012.0, which indicated the existence of electrostatic adsorption after the interaction between KD and magnesite. The electric potential of limonite will decrease under the effect of $\mathrm{KD}$, thus leading the zero electric point toward the acid zone. When the KD dosage was $100 \mathrm{mg} / \mathrm{l}$, limonite was zero power. When the KD dosage was $200 \mathrm{mg} / \mathrm{l}$, the zero point of limonite dropped to 3.2. With the increase of $\mathrm{pH}$, the potential of limonite decreased gradually.

\subsection{The Role of Reagents and Minerals by Infrared Spectroscopy}

3.3.1. Analysis of Sodium Hexametaphosphate and Mineral Adsorption by Infrared Spectroscopy. Infrared spectroscopy was used to analyze the chemisorption of minerals and chemicals [30]. A $2 \mathrm{~g}$ single-mineral ore sample was placed in a solution of sodium hexametaphosphate at a concentration of $50 \mathrm{mg} / \mathrm{l}$, the $\mathrm{pH}$ value of the solution was adjusted to 11.6, and the solution was thoroughly stirred for 5 minutes. The mineral sample after being treated with the reagents 


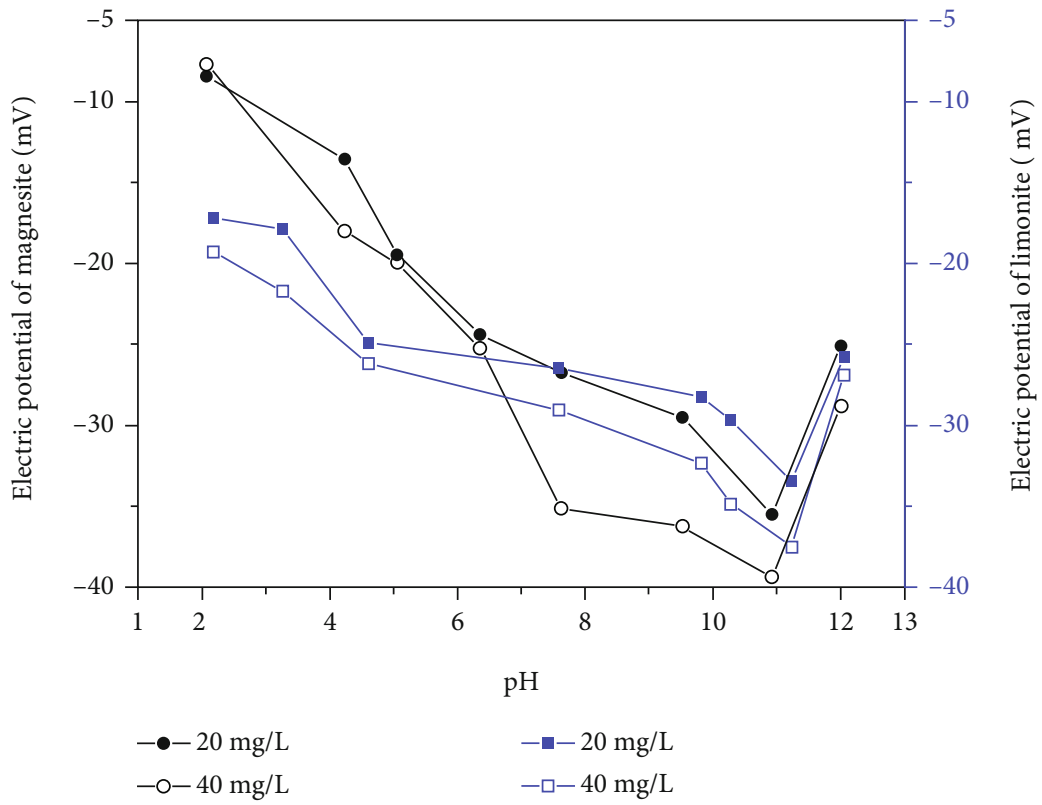

FIGURE 8: Effect of sodium hexametaphosphate on the zeta potential of magnesite and limonite.

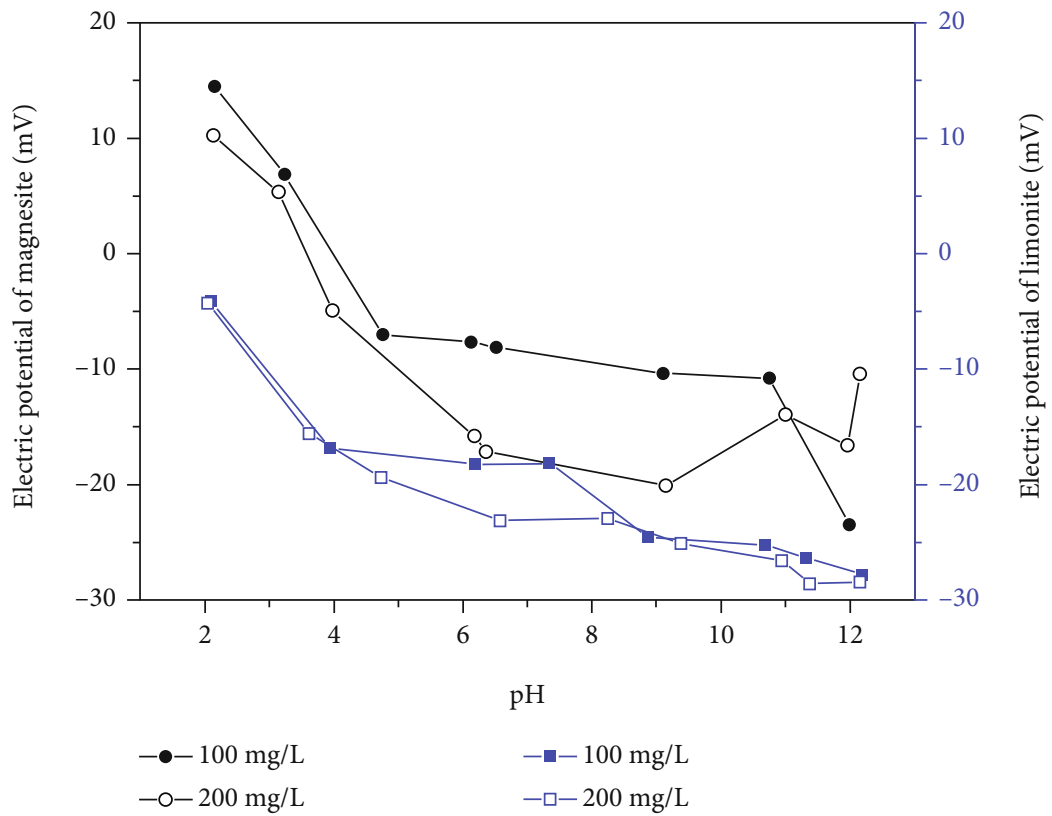

FIGURE 9: Effect of sodium silicate dosage on the zeta potential of magnesite and limonite.

was washed with distilled water three times, filtrated, and dried at room temperature for infrared spectroscopical analysis. The spectra of magnesite and limonite before and after interaction with sodium hexametaphosphate are shown in Figures 12 and 13, respectively.

As can be seen in Figures 12 and 13, sodium hexametaphosphate shows a characteristic peak of $\mathrm{P}=\mathrm{O}$ stretching vibration at $1207 \mathrm{~cm}^{-1}$ and a characteristic $\mathrm{P}-\mathrm{O}-\mathrm{P}$ at $882 \mathrm{~cm}^{-1}$. The peaks at $1095.15 \mathrm{~cm}^{-1}$ and $969.98 \mathrm{~cm}^{-1}$ were the $\mathrm{P}-\mathrm{O}$ stretching vibration characteristic peaks of sodium hexametaphosphate [31]. After adding magnesite and sodium hexametaphosphate, the $-\mathrm{OH}$ stretching vibration absorption peak at $3351 \mathrm{~cm}^{-1}$ increased compared with that before sodium hexametaphosphate. This shows a chemical adsorption between sodium hexametaphosphate and magnesite. After the reaction of limonite and sodium hexametaphosphate, the characteristic peak of $\mathrm{P}-\mathrm{O}-\mathrm{P}$ in sodium hexametaphosphate appeared at $882 \mathrm{~cm}^{-1}$ in the spectrum and the peak 


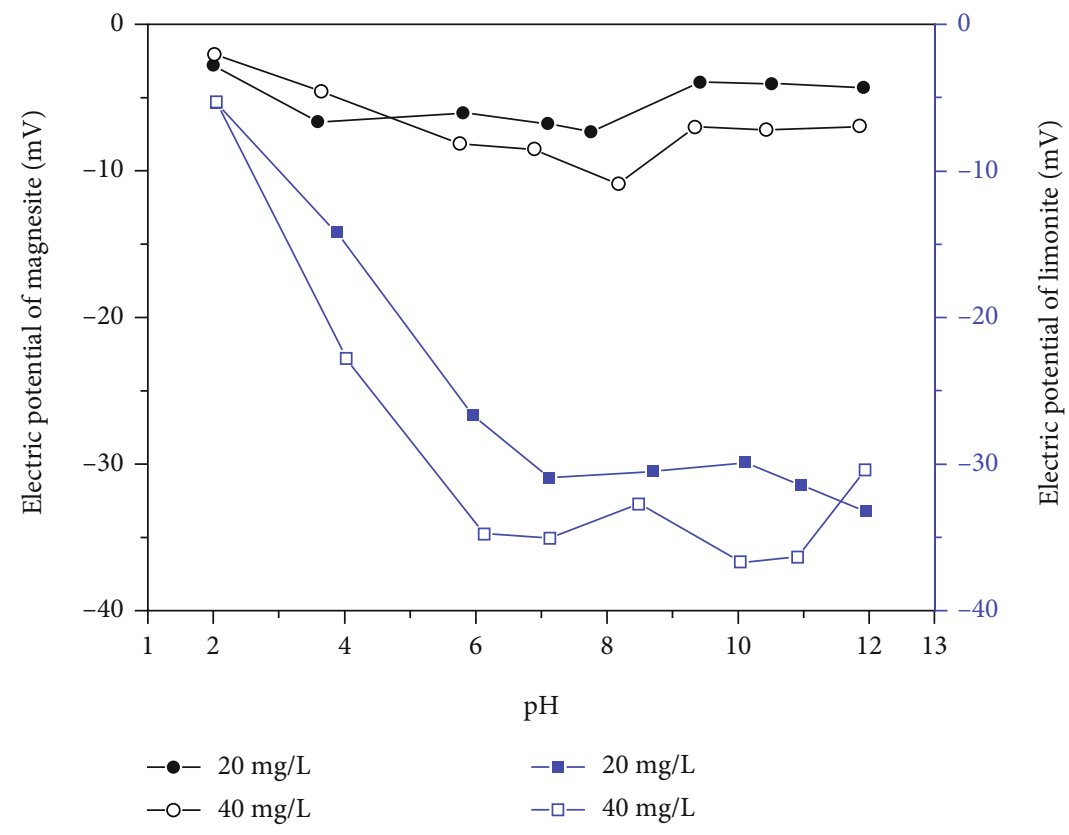

FIGURE 10: Effect of CMC on zeta potential of magnesite and limonite.

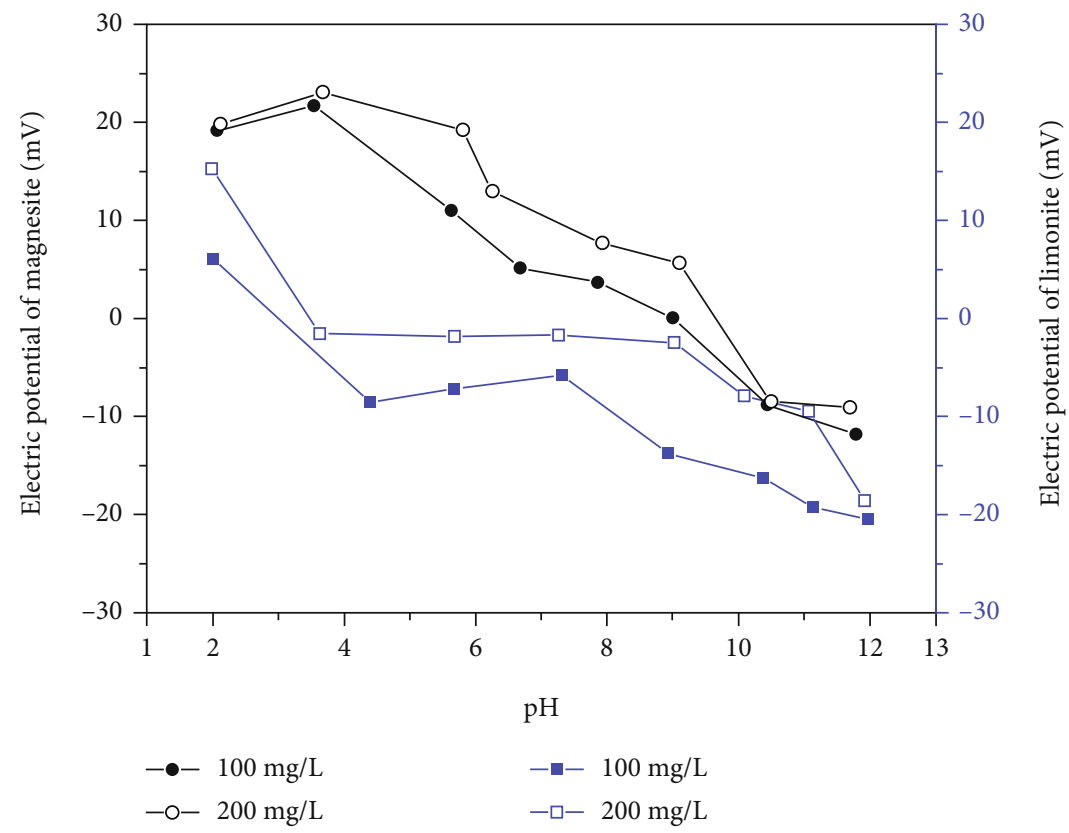

FIGURE 11: Effect of KD on zeta potential of magnesite and limonite.

of $\mathrm{P}=\mathrm{O}$ stretching appeared to be at $1207 \mathrm{~cm}^{-1}$, indicating that sodium hexametaphosphate in brown chemical adsorption occurred on the surface of limonite [32].

3.3.2. Analysis of Sodium Silicate and Mineral Adsorption by Infrared Spectroscopy. The single-mineral sample was $2 \mathrm{~g}$, mixed in a solution of sodium silicate with a concentration of $200 \mathrm{mg} / \mathrm{l}$. Hydrophilic silicas such as $\mathrm{Si}(\mathrm{OH})_{4}$ and $\mathrm{SiO}_{2}(\mathrm{OH})_{2}^{2-}$ and acid micelles were selectively adsorbed on the mineral surface and changed its surface properties, thus changing the effect of the collector on the mineral surface. The adsorption mechanism was analyzed by infrared spectroscopy [33]. The spectra of magnesite and limonite before and after the action of sodium silicate are shown in Figures 14 and 15 , respectively.

In Figures 14 and 15, it can be seen that the asymmetric stretching vibration absorption peak of $\mathrm{Si}-\mathrm{O}-\mathrm{Si}$ appeared to be at $876 \mathrm{~cm}^{-1}$ [34] and $\mathrm{CO}_{3}{ }^{2-}$ showed a significant change in the characteristic peak at $1460 \mathrm{~cm}^{-1}$, indicating the chemical adsorption between magnesite and sodium silicate. The 


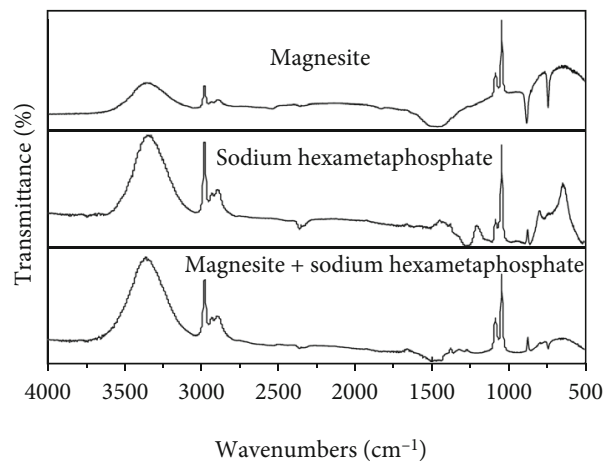

FIGURE 12: FTIR spectra of sodium hexametaphosphate and magnesite.

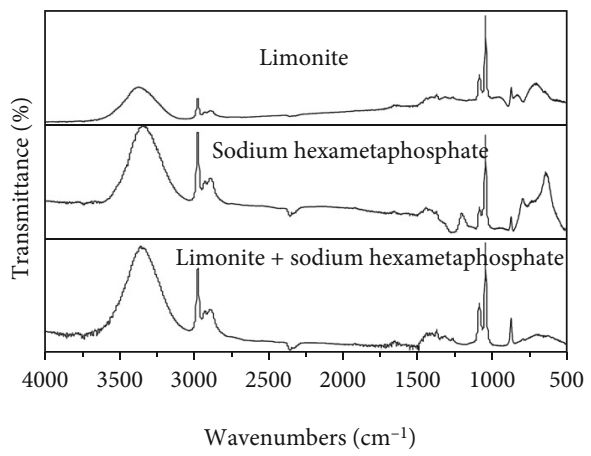

FIGURE 13: FTIR spectra of limonite and sodium hexametaphosphate.

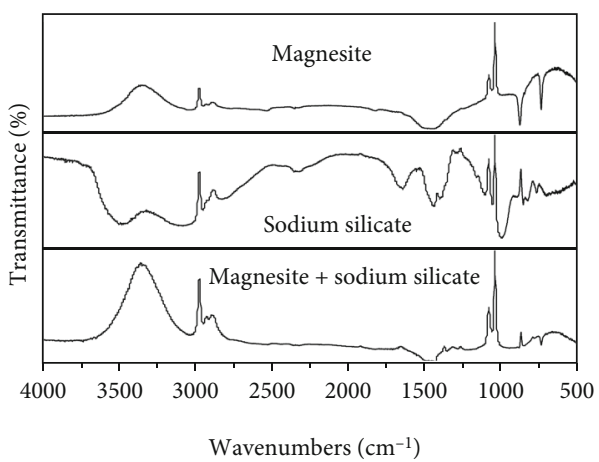

FIGURE 14: FTIR spectra of magnesite and sodium silicate.

$\mathrm{Si}-\mathrm{O}-\mathrm{Si}$ stretching vibration peak of $\mathrm{SiO}_{3}{ }^{2-}$ in sodium silicate appeared to be at $1185 \mathrm{~cm}^{-1}$ in the limonite spectrum [35], reflecting chemisorption between sodium silicate and limonite.

3.3.3. Analysis of CMC and Mineral Adsorption by Infrared Spectroscopy. The single-mineral sample was $2 \mathrm{~g}$, mixed in a solution of CMC with a concentration of $50 \mathrm{mg} / \mathrm{l}$. The IR spectra of CMC before and after the interaction with magnesite and limonite are shown in Figures 16 and 17, respectively.

As can be seen in Figures 16 and 17, the characteristic peaks in CMC appeared to be at $1372 \mathrm{~cm}^{-1}$ and $1256 \mathrm{~cm}^{-1}$ after magnesite was contacted with $\mathrm{CMC}$, indicating chemical adsorption between CMC and magnesite. In the limonite and CMC system, infrared spectroscopy showed no signifi-

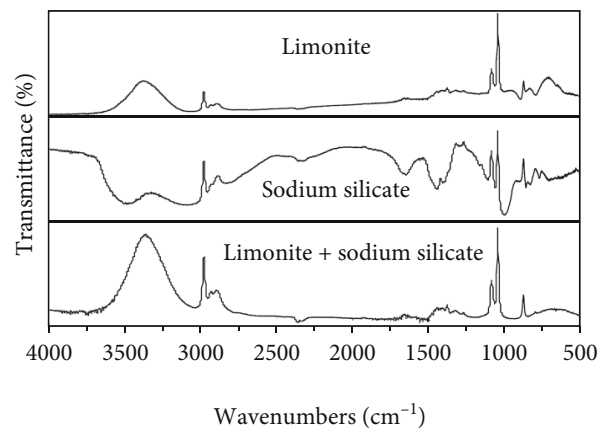

FIGURE 15: FTIR spectra of limonite and sodium silicate.

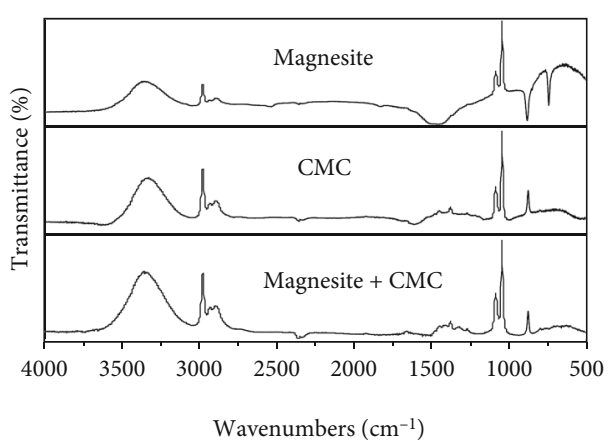

FIGURE 16: FTIR spectra of magnesite and CMC.

cant difference before and after contact, indicating no chemical adsorption between CMC and limonite.

3.3.4. Analysis of KD and Mineral Adsorption by Infrared Spectroscopy. The single-mineral sample was $2 \mathrm{~g}$, mixed in a solution of KD with a concentration of $150 \mathrm{mg} / \mathrm{l}$. The infrared spectra of magnesite and limonite before and after the action of the collector KD are shown in Figures 18 and 19.

As can be seen in Figures 18 and 19, the spectral peaks of magnesite and limonite were not displaced after the KD and no new characteristic peak was observed. However, in the single-mineral flotation test, magnesium ore had a catching effect, indicating no chemical adsorption between magnesite and $\mathrm{KD}$, likely due to weak electrostatic force adsorption. 


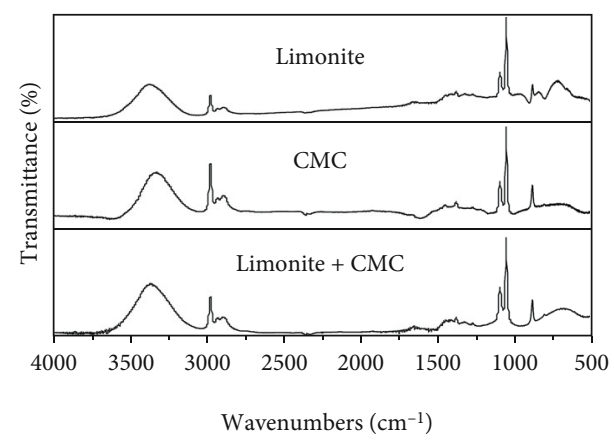

FIgURE 17: FTIR spectra of limonite and CMC.

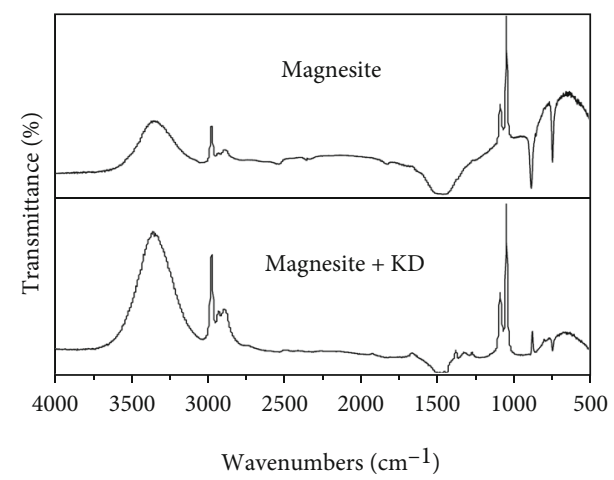

FIgURE 18: FTIR spectra of magnesite and KD.

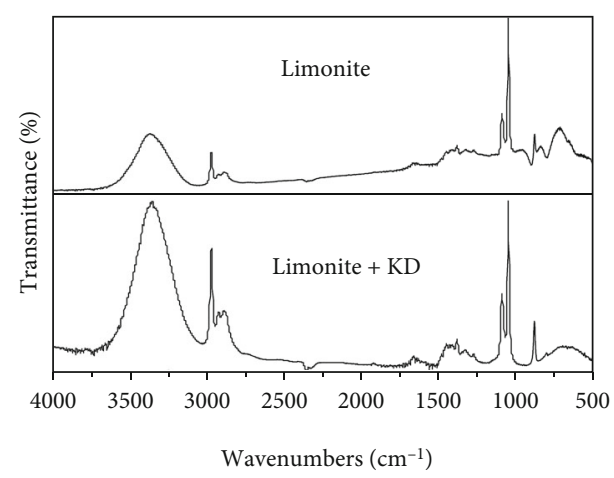

FIgURE 19: FTIR spectra of limonite and KD.

\section{Conclusions}

With $\mathrm{KD}$ as a collector, the maximum floatation ratio of magnesite was $74.35 \%$ at a $\mathrm{pH}$ value of 11.6 and the floatation ratio of limonite was $3.25 \%$. There existed large floatability differences; magnesite and limonite increased the floatation ratio with the increase of collectors.

Sodium hexametaphosphate inhibited both magnesite and limonite. A small amount of sodium silicate obviously inhibited the floatation ratio of limonite and had a little effect on the floatation ratio of magnesite. CMC had a significant inhibitory effect on magnesite and limonite flotation. The increase of the amount of CMC first inhibited reactivation. The addition of the three modifiers did not further increase this difference, but sodium silicate appeared to be the best to maintain the two types of mineral floatability differences. Mineral mixture tests showed that when sodium silicate was used as an inhibitor for flotation of magnesite and limonite, the collector was preferentially adsorbed on magnesite.

The measured isoelectric points of magnesite and limonite were 6.0 and 7.5, respectively. Sodium hexametaphosphate significantly reduced the electromotive potential of the two minerals, the addition of sodium silicate reduced the electromotive potential of magnesite, with zero point moving to the left, and the greater concentration of sodium silicate, the more the moving to the left. Sodium silicate on the electric potential of limonite reduced the role more significantly. When the sodium silicate dosage was $100 \mathrm{mg} / \mathrm{l}$, the limonite electric potential value became negative within the measured $\mathrm{pH}$ range; after $\mathrm{CMC}$ was added, the magnesite potential decreased with the increase of the $\mathrm{pH}$ value. The CMC caused the electromotive potential of limonite to decrease significantly, and a small amount of CMC turned the electromotive potential of limonite into negative. KD increased the electromotive potential of magnesite and reduced the zeta potential of limonite.

The infrared spectroscopy test shows that all three kinds of modifiers chemically adsorbed on the magnesite surface. Sodium hexametaphosphate and sodium silicate chemically adsorbed the surface of limonite. CMC were not chemically adsorb limonite, and KD were not chemically adsorb on both mineral surfaces.

\section{Data Availability}

All data generated or analyzed during this study are included in this published article.

\section{Conflicts of Interest}

The authors declared no potential conflicts of interest with respect to the research, authorship, and/or publication of this article.

\section{Acknowledgments}

This project was supported by the National Natural Science Foundation of China, "Dissolution Characteristics of Carbonate Minerals in Magnesite Ore and the Regulation for Flotation Influence" (Grant no. 51874168).

\section{References}

[1] Q. Q. Wang, D. Z. Wei, X. A. Li, and S. J. Dai, “The magnetic separation study on flotation concentrate powder of magnesite ore," Advanced Materials Research, vol. 826, pp. 140-143, 2013.

[2] A. Yehia and M. Al-Wakeel, "Role of ore mineralogy in selecting beneficiation route for magnesite-dolomite separation," Physicochemical Problems of Mineral Processing, vol. 49, pp. 525-534, 2013.

[3] I. Bentli, N. Erdogan, N. Elmas, and M. Kaya, "Magnesite concentration technology and caustic - calcined product from Turkish magnesite middlings by calcination and magnetic 
separation," Separation Science and Technology, vol. 52, no. 6, pp. 1129-1142, 2017.

[4] F. Farhang, T. K. Oliver, and M. Rayson, "Experimental study on the precipitation of magnesite from thermally activated serpentine for $\mathrm{CO}_{2}$ sequestration," Chemical Engineering Journal, vol. 303, pp. 439-449, 2016.

[5] N. P. Nayak and B. K. Pal, "Separation behaviour of iron ore fines in Kelsey Centrifugal Jig," Journal of Minerals \& Materials Characterization \& Engineering, vol. 1, no. 3, pp. 85-89, 2013.

[6] W. Z. Yin, Q. Li, and Y. Q. Ma, "Flotation research on dolomite-containing magnesite ore," Advanced Materials Research, vol. 158, pp. 113-124, 2010.

[7] H. Zhang, W. G. Liu, C. Han, and D. Wei, "Intensify Dodecylamine adsorption on Magnesite and dolomite surfaces by monohydric alcohols," Applied Surface Science, vol. 444, pp. 729-738, 2018.

[8] H. Zhang, C. Han, W. Liu, D. Hou, and D. Wei, "The chain length and isomeric effects of monohydric alcohols on the flotation of magnesite and dolomite by sodium oleate," Journal of Molecular Liquids, vol. 276, pp. 471-479, 2019.

[9] H. D. Wasmuth and K. H. Unkelbach, "DESCOS - highintensity drum-type magnetic separator with superconductive magnetic system providing high throughput rates," Metallic Ore Dressing Abroad, vol. 30, pp. 753-760, 1989.

[10] N. A. Georgios, "A study on the separation of magnesite fines by magnetic carrier methods," Colloids and Surfaces A: Physicochemical and Engineering Aspects, vol. 149, pp. 585-593, 1999.

[11] R. Yu, H. Q. Ren, J. C. Wu, and X. Zhang, "A novel treatment processes of Struvite with pretreated magnesite as a source of low-cost magnesium," Environmental Science \& Pollution Research, vol. 24, no. 28, pp. 22204-22213, 2017.

[12] Q. C. Feng, S. M. Wen, W. J. Zhao, and H. Chen, "Interaction mechanism of magnesium ions with cassiterite and quartz surfaces and its response to flotation separation," Separation and Purification Technology, vol. 206, pp. 239-246, 2018.

[13] Q. Feng, S. Wen, W. Zhao, and Y. Chen, "Effect of calcium ions on adsorption of sodium oleate onto cassiterite and quartz surfaces and implications for their flotation separation," Separation and Purification Technology, vol. 200, pp. 300-306, 2018.

[14] J. A. Tang and M. Valix, "Leaching of low grade limonite and nontronite ores by fungi metabolic acids," Minerals Engineering, vol. 19, no. 12, pp. 1274-1279, 2006.

[15] W. Xiong, J. Deng, B. Chen, S. Deng, and D. Wei, "Flotationmagnetic separation for the beneficiation of rare earth ores," Minerals Engineering, vol. 119, pp. 49-56, 2018.

[16] W. Z. Yin, B. Yang, Y. F. Fu et al., "Effect of calcium hypochlorite on flotation separation of covellite and pyrite," Powder Technology, vol. 343, pp. 578-585, 2019.

[17] W. Z. Yin, H. R. Sun, Y. Tang et al., "Effect of pulp temperature on separation of magnesite from dolomite in sodium oleate flotation system," Physicochemical Problems of Mineral Processing, vol. 55, pp. 1049-1058, 2019.

[18] H. Zhang, W. C. Liu, H. Cong, and H. Haiqing, "Effects of monohydric alcohols on the flotation of magnesite and dolomite by sodium oleate," Journal of Molecular Liquids, vol. 249, pp. 1060-1067, 2018.

[19] W. H. Sun, W. G. Liu, S. J. Dai, T. Yang, H. Duan, and W. Liu, "Effect of Tween 80 on flotation separation of magnesite and dolomite using $\mathrm{NaOL}$ as the collector," Journal of Molecular Liquids, vol. 315, article 113712, 2020.
[20] S. J. Dai, X. A. Li, S. Y. Yang, and L. T. Yu, "The flotation experiment study on a high silicon low-grade magnesite in Liaoning province," Advanced Materials Research, vol. 454, pp. 352356, 2012.

[21] J. H. Han, X. A. Li, S. J. Dai, Z. Y. Wang, and L. T. Yu, "Experimental study on purification of magnesite ore in Liaoning province," Advanced Materials Research, vol. 826, pp. 48-52, 2013.

[22] W. G. Liu, W. B. Liu, S. J. Dai, and B. Wang, "Adsorption of bis(2-hydroxy-3-chloropropyl) dodecylamine on quartz surface and its implication on flotation," Results in Physics, vol. 9, pp. 1096-1101, 2018.

[23] W. B. Liu, W. G. Liu, B. Y. Wang et al., "Novel hydroxy polyamine surfactant $\mathrm{N}$-(2-hydroxyethyl)-N-dodecyl-ethanediamine: its synthesis and flotation performance study to quartz," Minerals Engineering, vol. 142, article 105894, 2019.

[24] M. Bruno, M. Rubbo, and F. R. Massaro, "Behavior of the chemical potential in calcite and magnesite crystals: a damped harmonic oscillation," Crystal Growth \& Design, vol. 16, no. 5, pp. 2671-2677, 2016.

[25] N. Gence and H. Ozdağ, "Surface properties of magnesite and surfactant adsorption mechanism," International Journal of Mineral Processing, vol. 43, no. 1-2, pp. 37-47, 1995.

[26] G. L. Chen and D. Tao, "Reverse flotation of magnesite by dodecyl phosphate from dolomite in the presence of sodium silicate," Separation Science and Technology, vol. 39, no. 2, pp. 377-390, 2005.

[27] N. Gence, "Wetting behavior of magnesite and dolomite surfaces," Applied Surface Science, vol. 225, pp. 3744-3750, 2006.

[28] F. A. Baryshnikov, I. V. Popov, and V. Y. Fedosova, "The electrochemical potential, adsorption and floatability of limonite as a function of solution pH," Soviet Mining Science, vol. 1, no. 2, pp. 159-160, 1965.

[29] Y. H. Wang and J. W. Ren, "Reverse flotation experiments on a limonite with anionic and cationic collectors," Conservation \& Utilization of Mineral Resources, vol. 49, pp. 135-138, 2004.

[30] G. Nermin and O. Nurgul, "pH dependence of electrokinetic behavior of dolomite and magnesite in aqueous electrolyte solutions," Applied Surface Science, vol. 252, pp. 8057-8061, 2006.

[31] Y. P. Lu, M. Zhang, Q. Feng, L. O. Tao, L. M. Ou, and G. F. Zhang, "Effect of sodium hexametaphosphate on separation of serpentine from pyrite," Transactions of Nonferrous Metals Society of China, vol. 21, no. 1, pp. 208-213, 2011.

[32] L. A. Hollingbery and T. R. Hull, "The thermal decomposition of natural mixtures of huntite and hydromagnesite," Thermochimica Acta, vol. 528, pp. 45-52, 2012.

[33] O. Kangal, A. A. Sirkeci, and A. Güney, "Flotation behaviour of huntite $\left(\mathrm{Mg}_{3} \mathrm{Ca}\left(\mathrm{CO}_{3}\right)_{4}\right)$ with anionic collectors," International Journal of Mineral Processing, vol. 75, no. 1-2, pp. 31-39, 2005.

[34] L. P. A. De, G. Valotto, and A. Quaranta, "Carbonate and silicate abundance indexing in coarse-grained river sediments using diffuse reflection infrared spectroscopy (DRIFTS) and ion-beam-induced luminescence (IBIL) spectroscopies," Applied Spectroscopy, vol. 71, pp. 1222-1230, 2017.

[35] B. Feng, X. P. Luo, J. Q. Wang, and W. Pengcheng, "The flotation separation of scheelite from calcite using acidified sodium silicate as depressant," Minerals Engineering, vol. 80, pp. 4549, 2015. 